\title{
Multicolour-banding fluorescence in situ hybridisation (mbanding-FISH) to identify recurrent chromosomal alterations in breast tumour cell lines
}

\author{
A Letessier',3, M-J Mozziconacci' ${ }^{1,2,3}$, A Murati' ${ }^{1,2}$, J Juriens', J Adélaïde', D Birnbaum' and M Chaffanet ${ }^{*, 1}$ \\ 'Laboratory of Molecular Cytogenetics, Department of Molecular Oncology, Paoli-Calmettes Institute-UMR599 INSERM, Marseille Cancer Research \\ Institute, Marseille, France; ${ }^{2}$ Department of Biopathology, Paoli-Calmettes Institute, Marseille, France
}

Many loci that contribute to mammary oncogenesis remain probably to be discovered. Only a handful of genes have been demonstrated to have a direct role in mammary oncogenesis after alteration. At the chromosomal level, amplifications, translocations and deletions point to the existence of a potential cancer gene in an affected region. Genes such as ERBB2 and CCND1, which encode a tyrosine kinase receptor and a G1 cyclin, respectively, are likely the selected oncogenes of the $17 \mathrm{q} 12$ and $11 \mathrm{q} 13$ amplification, respectively. For other amplification regions, such as the $8 \mathrm{p} 12$ and $20 \mathrm{q} 13$ regions, and for deletions, the identity of the cancer genes remains uncertain. The characterisation of translocations has provided additional cancer gene candidates, such as FHIT (Popovici et al, 2002), NTRK3 and ETV6 (Tognon et al, 2002; our unpublished observations), BCAS (Bärlund et al, 2002) and NRG1 (Wang et al, 1999; Adélaïde et al, 2003; Huang et al, 2004) genes. Given the number of recurrent chromosomal breaks observed in breast cancer (http://cgap.nci.nih.gov/Chromosomes/ RecurrentAberrations), this line of research might become more fruitful than the search for deletions through loss of heterozygosity data, which has been rather disappointing (Devilee et al, 2001). Although the mechanisms and consequences of translocations are not as clear as for those found in hemopathies and sarcomas, the

*Correspondence: Dr M Chaffanet, Institut Paoli-Calmettes, 232, Bd Sainte Marguerite BPI56, I 3273 Marseille Cedex 9, France;

E-mail: chaffanetm@marseille.fnclcc.fr

${ }^{3}$ These authors have equally contributed to this work

Received 19 May 2004; revised 14 September 2004; accepted 28 September 2004; published online 18 January 2005 existence of recurrent events suggests a role for the genes located at the breakpoints and provides a relatively easy way to discover more cancer genes.

A major limitation of this approach, however, is the difficulty to obtain reliable informative data on chromosomes of breast tumours. Technologies such as chromosome painting, spectral karyotyping (SKY) and multiplex- or multicolour-fluorescence in situ hybridisation (M-FISH) (Schröck et al, 1996; Speicher et al, 1996) can overcome the limitations of conventional cytogenetical methods in the characterisation of complex chromosome alterations observed in cancers. They allow the simultaneous visualisation of all human chromosomes in different pseudocolours and a better characterisation of the rearrangements. However, intrachromosomal rearrangements or the origin of abnormal chromosomal segments cannot be defined with these techniques. To overcome these limitations, different multicolour-banding techniques including mbanding-FISH have been developed (Müller et al, 1997, 1998; Chudoba et al, 1999; Liehr et al, 2002a, b; Kakazu et al, 2003). They can be performed with combinations of well-defined subregional probes (Müller et al, 2004). They can reveal aberrations not visible by other methods, and consequently facilitate the molecular identification of targeted genes. Obtaining good metaphase cells in breast tumours is still difficult but cell lines may, in a first step, be used to evaluate the usefulness of the approach.

We have used mbanding-FISH to search for regions of recurrent alterations in breast tumour cell lines on five chromosomes. We have identified several such regions. We show that mbanding-FISH is a powerful method to identify rapidly regions of chromosomal breaks. We report two examples of further characterisation of 
breakpoints, which target the $1 \mathrm{p} 36$ and $5 \mathrm{p} 11-12$ regions. This technology should constitute an efficient first step in the search for potential cancer genes.

\section{MATERIAL AND METHODS}

\section{Tumour cell lines}

In all, 20 established breast tumour cell lines were used. They were as follows: Br-Ca-MZ-01 (Möbus et al, 1998), BT-474, CAMA-1, HCC1937 (Tomlinson et al, 1998), MCF-7, MCF-10F, MDA-MB157, MDA-MB-175, MDA-MB-231, MDA-MB-361, MDA-MB-453, MDA-MB-468, SK-BR-3, UACC-812, ZR-75-1 (ATCC, Rockville, MD, USA), SUM-44, SUM-52, SUM-149, SUM-185 (Forozan et al, 1999; http://www.cancer.med.umich.edu/breast_cell/clines/ clines.html) and IPC-BC-116. We established the latter cell line from an inflammatory carcinoma, after informed consent of the patient; the tumoral karyotype was established and displayed a $\mathrm{t}(1 ; 6)(\mathrm{p} 36 ; \mathrm{p} 21)$ translocation as sole abnormality. All lines are derived from carcinomas except MCF-10F, which is derived from a fibroadenoma. The cells were grown using the recommended culture conditions, while IPC-BC-116 was grown in DMEM/Ham F12 medium (1/1) supplemented with $10 \% \mathrm{FBS}, 10 \mu \mathrm{g} \mathrm{ml}^{-1}$ Insulin, $1 \mu \mathrm{g} \mathrm{ml}^{-1}$ hydrocortisone and $10 \mathrm{ng} \mathrm{ml}^{-1}$ EGF.

\section{Mbanding-FISH}

The harvesting of cells, fixation and preparation of metaphase spreads for chromosome banding analysis and FISH were carried out from cytogenetic pellets of cultured cell lines according to protocols described in Courtay-Cahen et al (2000). MbandingFISH, a high-resolution multicolour-banding technique that provides precise information on intrachromosomal rearrangements and exact breakpoint mapping, was performed on chromosome metaphases cell lines (Table 1) with probe chromosome 1-, 5-, 8-, 12- and 17-mband cocktails, according to the protocol recommended by Metasystems (Chudoba et al, 1999) and as described previously (Popovici et al, 2002). The commercial probe mband cocktail derives from microdissected region-specific partial chromosome paints (PCP). Each PCP is labelled using a unique

Table I Breast tumour cell lines analysed by mbanding-FISH

\begin{tabular}{|c|c|c|c|c|c|}
\hline Cell lines & Chrl & Chr5 & Chr8 & Chrl2 & Chrl7 \\
\hline BrCa-MZ-OI & & & $x$ & & \\
\hline BT-474 & & & & $x$ & \\
\hline CAMA-I & & $x$ & $X$ & $x$ & $x$ \\
\hline $\mathrm{HCCl} 937$ & $x$ & $x$ & & & $x$ \\
\hline IPC-BC- $\mid 16$ & $x$ & & & & \\
\hline MCF-7 & $x$ & $x$ & & & \\
\hline MCF-IOF & $x$ & & $x$ & & \\
\hline MDA-MB- 157 & & $x$ & $x$ & $x$ & \\
\hline MDA-MB- 175 & & & & & $x$ \\
\hline MDA-MB-23I & $x$ & & $x$ & & $x$ \\
\hline MDA-MB-36I & & & & $x$ & \\
\hline MDA-MB-453 & & & & & $x$ \\
\hline MDA-MB-468 & $x$ & & $x$ & & \\
\hline SK-BR-3 & $x$ & $x$ & & $x$ & \\
\hline SUM-44 & & $x$ & $x$ & & \\
\hline SUM-52 & $x$ & $x$ & & & \\
\hline SUM-149 & & $x$ & $x$ & & $x$ \\
\hline SUM-185 & $x$ & $x$ & & & \\
\hline UACC-8I2 & $x$ & $x$ & & $x$ & $x$ \\
\hline ZR-75-I & $x$ & & $x$ & $x$ & $x$ \\
\hline Total & 11 & 10 & 9 & 7 & 8 \\
\hline
\end{tabular}

fluorochrome combination and partially overlaps with the neighbouring one.

The specific chromosome-mband cocktail was denatured and hybridised on treated and denatured metaphase chromosomes, according to the manufacturer's protocol. After hybridisation, chromosomes were washed with $50 \%$ formamide $/ 2 \times$ SSC and $2 \times$ SSC at $42{ }^{\circ} \mathrm{C}$. The excitation/emission spectra of the fluorochromes are equivalent to FITC, Spectrum Orange ${ }^{\mathrm{TM}}$, TexasRed $^{\mathbb{R}}$ and DEAC (diethylamino-coumarin (www.metasystems.de)). For chromosome 1-, 5-, 8- and 12-mband cocktail probes, an additional labelling was carried out using biotin, which is detected by Streptavidin-Cy ${ }^{\mathrm{TM}} 5$ (B-tect).

After counterstaining with 4,6-diamidino-2-phenylindole, the images were analysed with a microscope (DMRXA, Leica Microsystèmes, Marseille, France), captured with a CCD camera, filtered and processed with ISIS software (In Situ Imaging Systems, Metasystems Hard- und Software GmbH, Altlussheim, Germany) (described in www.metasystems.de). The resulting fluorescence intensity pattern along the chromosome axis shows a continuous change of colour ratios. Pseudocolours can be assigned to chromosome sections of similar colour ratios giving rise to a reproducible banding pattern that does not depend on chromosome condensation (Chudoba et al, 1999).

A region of breakpoints was defined by comparison between the abnormal colour spectrum of a derivative chromosome and the normal profile of the corresponding nonaltered chromosome; a disruption of colour-banding pattern defines a region of break. Amplifications by duplication or triplication were defined on the basis of duplicate or triplicate of at least two colour sections observed on the abnormal colour spectrum and pseudocolour profile of a derivative chromosome. At least 10 metaphases exhibiting the same derivative chromosomes were studied, and mbanding colour profiles were analysed for each derivative.

\section{FISH analysis}

To delineate the $t(1 ; 6)(\mathrm{p} 36 ; \mathrm{p} 21)$ and $t(5 ; 12)(\mathrm{p} 12 ; \mathrm{p} 11)$ events, and identify the potential genes involved, dual colour FISH analysis was carried out using labelled DNA of BAC clones as probes as described previously (Adélaïde et al, 2003) on IPC-BC-116 and UACC-812 breast tumour cell lines, respectively.

To refine rapidly the $1 \mathrm{p} 36$ breakpoint in the $t(1 ; 6)(\mathrm{p} 36 ; \mathrm{p} 21)$ rearrangement, the following $\mathrm{BAC}$ clone set covering this region was selected with variable genomic distance between clones: telRP11-164A22 (AC055792; chr1:14,996,330-15,182,825), RP11430L17 (AL358794; chr1:16,386,491-16,511,439), RP11-473A10 (AL358593; chr1:17,656,749-17,799,202), RP11-99F3 (AC020587; chr1:18,111,224-18,284,657), RP11-294O9 (AC026576; chr1:19,390, 941-19,574,586), RP11-97J18 (AL391598; chr1:19,804,646-19,980, 341), RP11-200J11 (AC022786; chr1:20,673,314-20,851,807) and RP11-487E1 (AL627311; chr1:21,041,056-21,210,231)-cen. To refine the $5 \mathrm{p} 12$ breakpoint, we selected BAC clones included in the region, close to, or contained in the 876F7 YAC clone previously described spanning the breakpoint at 5p12 (Popovici et al, 2002): tel-RP11-453A8 (AC027488; chr5:40,533,761-40,705,000), RP11-30 F7 (AC016332; chr5:41,237,134-41,386,355), RP11-9G14 (included in NT_006576 and mapped by FHCRC lab; chr5:41,319,672-41, 319,970), RP11-190J8 (AC021600; chr5:41,384,203-41,536,708), RP11-184C11 (AC025649; chr5:41,472,703-41,639,760)-cen. DNA from BAC clones were purified, labelled and used as probes in combination with centromeric probes specific for chromosome 6 (revealed in green, FITC) or digoxigenin-labelled centromeric probe specific for chromosome 12 (revealed in red, TRITC). All BAC clones were obtained from the BACPAC resource (Children's Hospital Oakland - BACPAC Resources, Oakland, CA, USA). Image analysis was carried out as described in the previous section. 


\section{RESULTS}

Regional localisation of chromosomal breakpoints on chromosomes $1,5,8,12$ and 17 in breast tumour cell lines

We chose to study five chromosomes by mbanding-FISH, that is, 1 , 5, 8, 12 and 17. The reasons of our choice were the following: these chromosomes have different sizes and are affected with various frequencies in breast cancer (Kytölä et al, 2000; Teixeira et al, 2002) (Table 1). Examples of mbanding-FISH are illustrated in Figure 1 showing breakpoints on $\operatorname{der}(1) t(1 ; 14)(\mathrm{p} 34 ; \mathrm{q}$ ?), $\mathrm{i} 5(\mathrm{p})$, $\operatorname{der}(12) t(1 ; 12)(? ; p 13.3), \operatorname{der}(12 ; 16)(q 10 ; ? q 10)$ and $\operatorname{der}(11)(t(11 ; 17)$ (?;q21.3-22) derivative chromosomes observed in MDA-MB-231 (Figure 1A), MDA-MB-157 (Figures $1 \mathrm{~B}$ and 1C) and ZR-75-1
(Figure 1D), respectively. A region of breakpoint was defined by comparison between the abnormal colour spectrum of a derivative chromosome and the normal profile of the corresponding nonaltered chromosome. The regions are indicated on the corresponding ideograms (Figures $1 \mathrm{~A}-\mathrm{D}$, bottom part). For each of the cell line studied, one to several derivative chromosomes could be observed. Comprehensive results in agreement to ISCN (1995) are described as supplementary data (Supplementary Table 1). For economical reasons, when previous experiments (e.g. with M-FISH) had demonstrated integrity of one or more of the five selected chromosomes in a cell line, this cell line was not studied with the respective mbanding probe. This explains why not all cell lines were systematically investigated with the five chromosome probes.

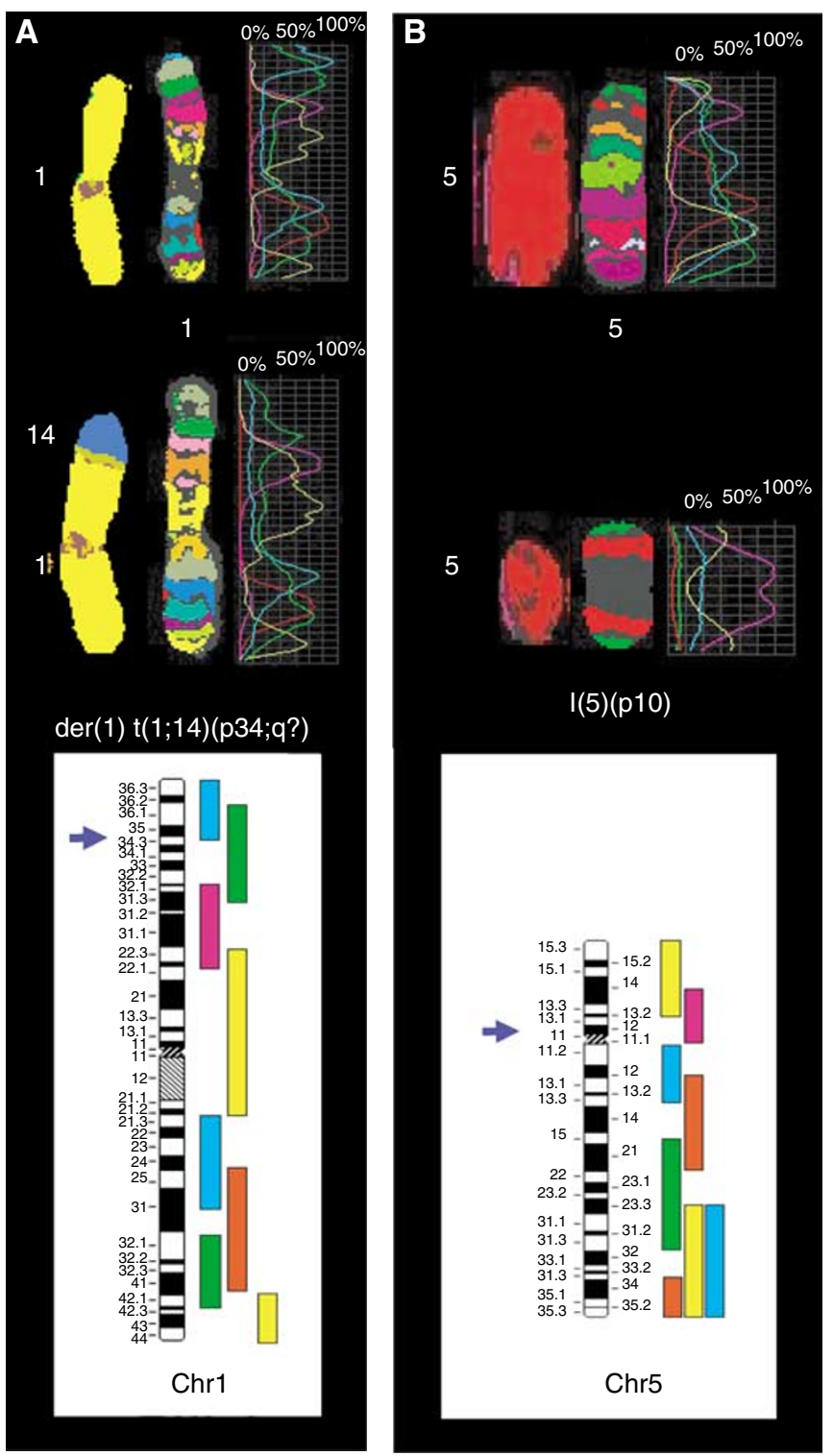

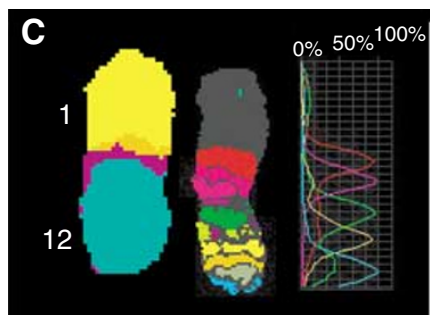

$\operatorname{der}(12) t(1 ; 12)(? ; p 13.3)$
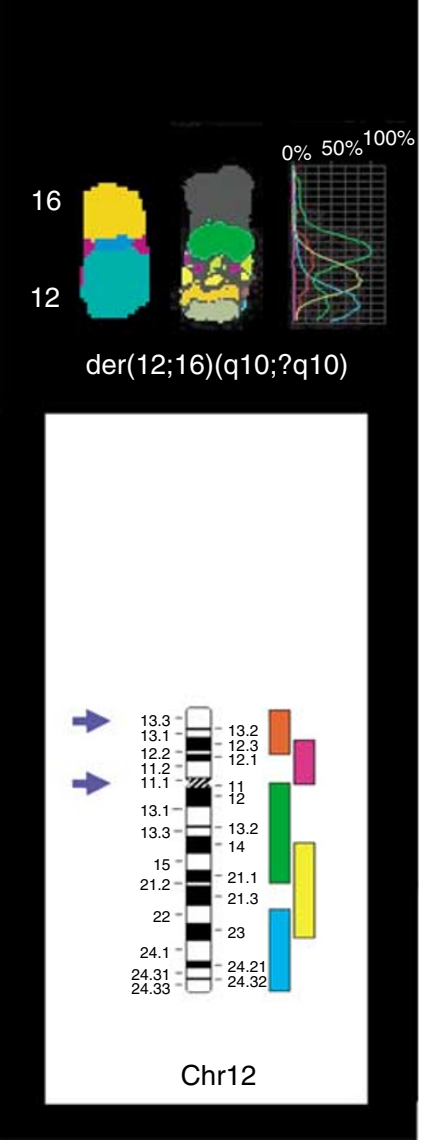

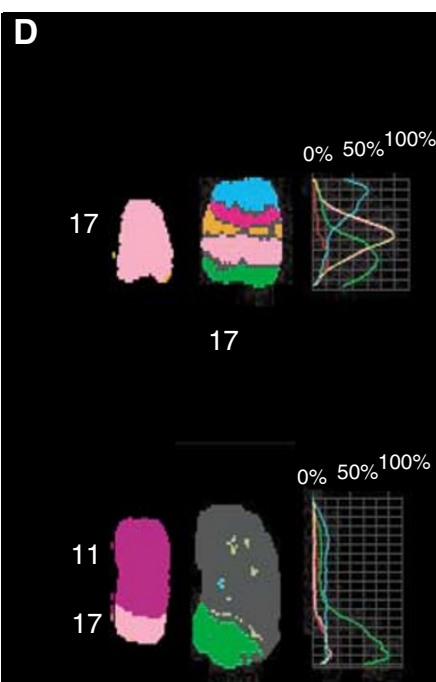

$\operatorname{der}(11) \mathrm{t}(11 ; 17)(? ; \mathrm{q} 21.3-22)$



Figure I Examples of mbanding-FISH in breast tumour cell lines. MDA-MB-23I (A), MDA-MB-I57 (B and C) and ZR-75-I (D) were analysed by FISH with specific mband cocktail probes for chromosome I (A), $5(\mathbf{B}), 12(\mathbf{C})$ and $17(\mathbf{D})$, respectively. M-FISH images of normal (save for chromosome I2 in MDA-MB- $157(\mathbf{C})$ ), and derivative chromosomes I, 5, 12 and 17 previously characterised in these cell lines (Popovici et al, 2002) are shown on the left hand of the corresponding mband images (pseudocolour profile) defined by colour spectra (on the right). Regional locations of breakpoints targeting

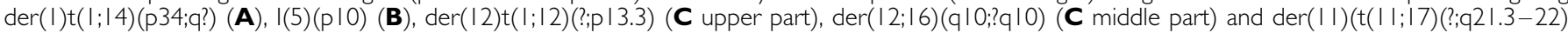
(D) present in MDA-MB-23I (A), MDA-MB-I57 (B and C) and ZR-75-I (D), respectively, were assigned by comparison with the normal profile. They are indicated by arrowheads on the corresponding ideograms (bottom part), which exhibit on their right hand the sequence of microdissected region-specific PCP labelled using a unique fluorochrome combination defining then the normal colour spectrum. Each PCP was labelled and partly overlaps with the neighbouring one. 
All breakpoints were located, and their positions are shown in Figure 2A. After considering all derivatives for each cell line, a total of 136 breakpoints were described. They were distributed as follows: $47,29,28,18$ and 14 on chromosome 1, 5, 8, 12 and 17, respectively. They were located on 4 (chromosome 17) to 11 (chromosome 1) regions per chromosome (Figure 2A) (Supplementary Table 1 and Figure 2A). The same region of breakpoint could be found in one (e.g. 12q13) to seven (1q21) cell lines. The same chromosome was affected in eight to 11 cell lines (Table 1). The regions with more than three breakpoints are referenced in Table 2. For each of them, a breakpoint incidence (BI) was defined for each chromosome as the ratio of the number of events found in this region and the total number of breakpoints observed along the given chromosome $(47,29,28,18$ and 14 for chromosome $1,5,8$, 12 and 17, respectively). For each chromosome, a recurrence index (RI) was defined as the ratio of the number of affected cell lines and the total number of tested cell lines. The product $\mathrm{BI} \times \mathrm{RI}$ allowed to point to breakpoints presenting both high breakpoint incidence and high recurrence (Table 2).

\section{Definition of altered regions on each chromosome}

There were 11 altered regions on chromosome 1 . The pericentromeric region (p12-p22.1 to q11-q21.2) was the site of the most frequent alterations, involving derivatives in about $80 \%$ of the analysed cell lines. Mbanding-FISH also allowed the delineation of deletions on both arms of chromosome 1, while amplifications by duplication or triplication were found only on the $\mathrm{q}$ arm.

We defined six altered regions on chromosome 5 . The most frequent were at $5 \mathrm{p} 11-\mathrm{p} 13.2$ and $5 \mathrm{q} 23.2-\mathrm{q} 31.1$, and affected $70 \%$ of the tested cell lines. These regions were located centromeric to FRA5E (5p14) and close to or within FRA5C, respectively; breaks may thus be the consequence of a particular fragility of these regions. Four frequently altered regions were found on chromosome
A
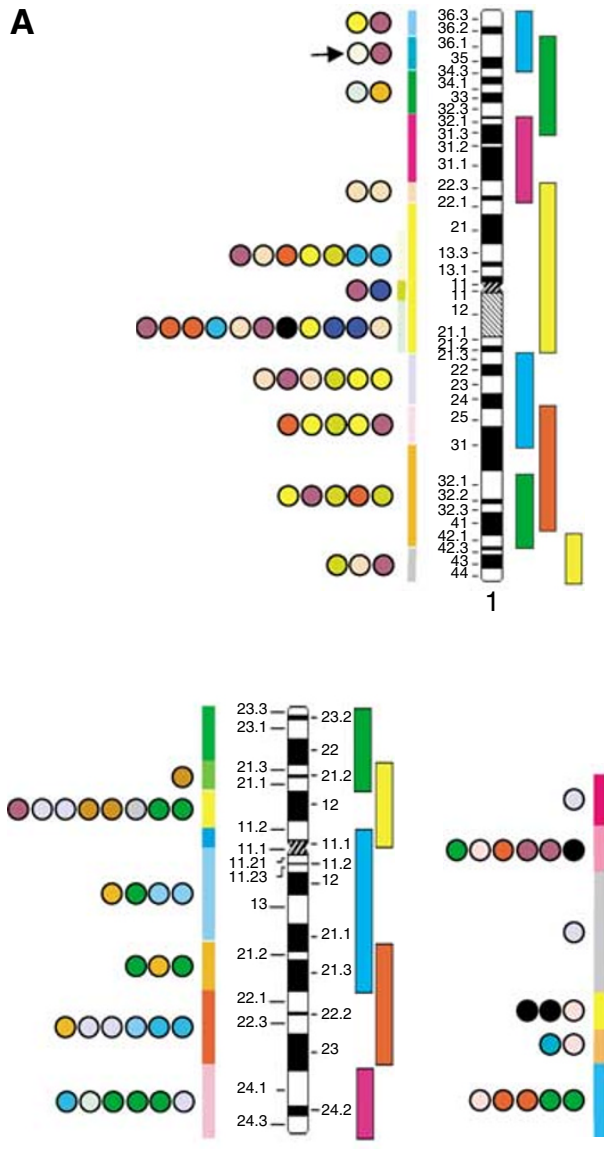

8

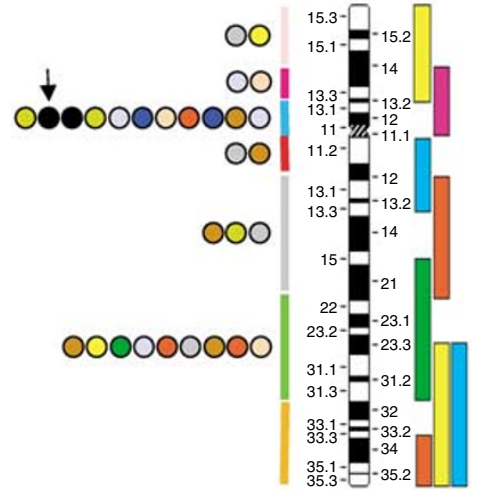

$\begin{array}{llll}\text { Br-ca-MZ-01 } & 0 & \text { MDA-MB-361 } & 0 \\ \text { BT-474 } & 0 & \text { MDA-MB-453 } & 0 \\ \text { CAMA-1 } & 0 & \text { MDA-MB-468 } & 0 \\ \text { HCC1937 } & 0 & \text { SKBR3 } & 0 \\ \text { IPC-BC-116 } & 0 & \text { SUM44 } & 0 \\ \text { MCF-7 } & 0 & \text { SUM52 } & 0 \\ \text { MCF-10F } & 0 & \text { SUM-149 } & 0 \\ \text { MDA-MB-157 } & 0 & \text { SUM185 } & 0 \\ \text { MDA-MB-175 } & 0 & \text { UACC-812 } & 0 \\ \text { MDA-MB-231 } & 0 & \text { ZR-75-1 } & 0\end{array}$
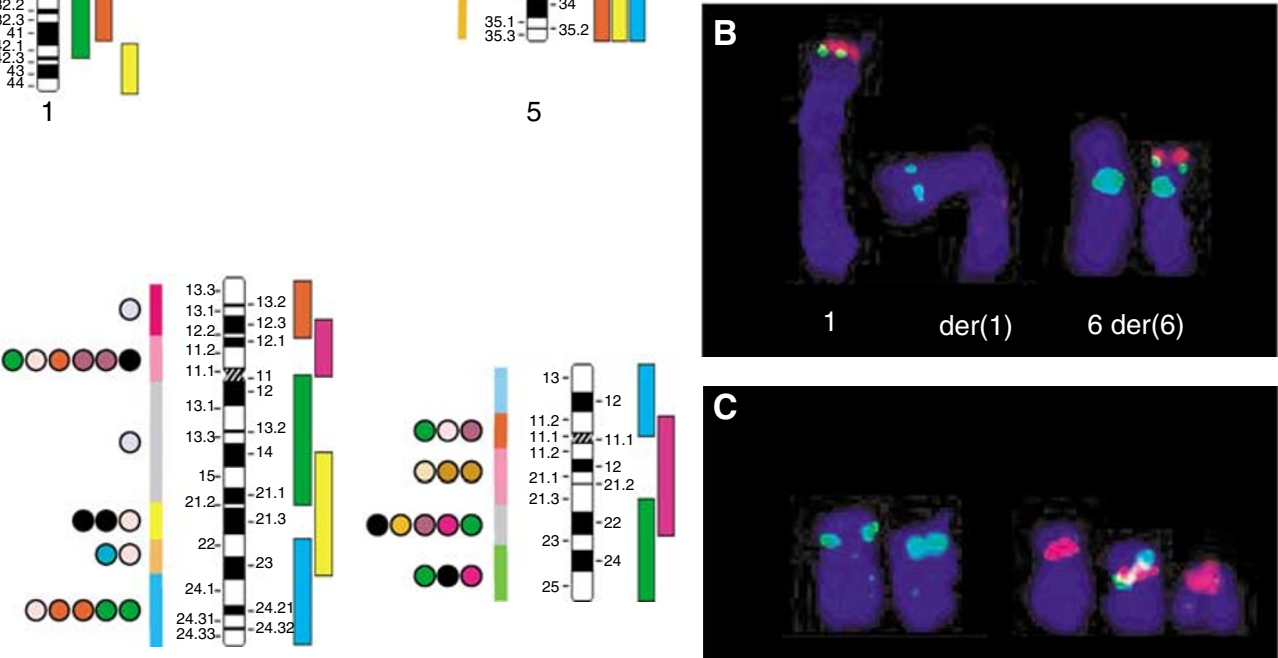

17

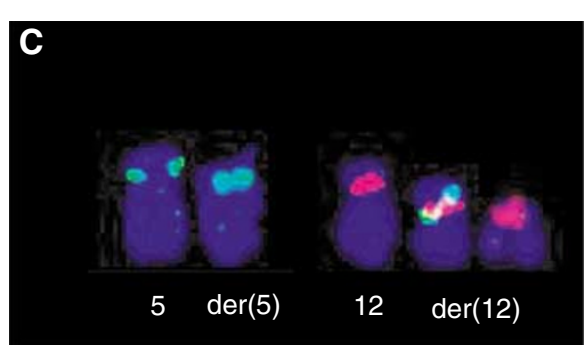

Figure 2 (A) Regional distribution of breakpoints in breast tumour cell lines. From mbanding-FISH analysis on breast tumour cell lines, a total of I 36 breakpoints were described (Supplementary Table I). Each coloured circle corresponds to a cell line as defined in the inset in upper right corner. These circles are positioned on ideograms of normal I, 5, 8, 12 and 17 chromosomes in the region affected by breakpoints characterised in cell lines derivatives reported in the supplementary table. Each coloured circle represents a breakpoint observed in one derivative. The occurrence order of coloured circles follows the order of breakpoints characterised in the corresponding cell lines reported in the supplementary table, for example, two circles with the same colour on the same region mean that this region is involved in two different derivatives present in the same cell line. Black arrows show I 36 and $5 p \mid 2$ breakpoints of the $\mathrm{t}(\mathrm{I} ; 6)(\mathrm{p} 36 ; \mathrm{p} 2 \mathrm{I})$ and $\mathrm{t}(5 ; \mathrm{I})(\mathrm{p}|\mathrm{2} ; \mathrm{p}| \mathrm{I})$ present in IPC-BC-II6 and UACC-8I2, respectively. (B and C) Dual-colour FISH refinement of two target regions. Dual-colour FISH experiment carried out on metaphase chromosomes from IPC-BC-I I6 (B) with digoxigenin-labelled DNA of RPI II64A22 (revealed in red, TRITC) in combination with biotinylated DNA of RPII-99F3 and centromeric probe specific for the chromosome 6 (revealed in green, FITC). The telomeric position of RPII-I64A22 allowed the identification of normal chromosome I and derivative chromosome 6 . The concomitant presence of RPII-99F3 on both derivatives and on chromosome I suggested that this clone spans the Ip36 breakpoint. Similarly, dual-colour FISH experiment carried out on metaphase chromosomes from UACC-8I2 (C) using biotinylated DNA of RPII-I90J8 BAC (revealed in green, FITC) and digoxigenin-labelled centromeric probe specific for chromosome I2 (revealed in red, TRITC) shows that RPII-I90J8 spans the 5p I 2 breakpoint. 
Table 2 Regional localisation of the most frequent breakpoints $(>3)$.

\begin{tabular}{|c|c|c|c|c|}
\hline $\begin{array}{l}\text { Regional } \\
\text { locations }\end{array}$ & $\begin{array}{l}\text { Number of } \\
\text { breakpoints }\end{array}$ & BI & $\mathbf{R I}$ & BI $\times \mathbf{R I}\left(\times 10^{-2}\right)$ \\
\hline$|p 22|-p \mid 2$. & 7 & $7 / 47$ & $6 / 11$ & 8.12 \\
\hline$|q||-q 2| .2$ & 11 & $1 \mid / 47$ & $7 / 11$ & 14.9 \\
\hline $1 \mathrm{q} 21.3-\mathrm{q} 24$ & 6 & $6 / 47$ & $4 / 11$ & 4.64 \\
\hline$|q 25-q 3|$ & 5 & $5 / 47$ & $4 / 11$ & 3.87 \\
\hline Iq32. I - q42.2 & 5 & $5 / 47$ & $4 / 11$ & 3.87 \\
\hline $5 p / 3.2-p / 0$ & | | & $1 \mid / 29$ & $7 / 10$ & 26.55 \\
\hline $5 q 22-q 31.3$ & 9 & $9 / 29$ & $7 / 10$ & 21.72 \\
\hline $8 p|2-p| 1$ & 8 & $8 / 28$ & $5 / 9$ & 15.87 \\
\hline $8 q 10-q 21.1$ & 4 & $4 / 28$ & $4 / 9$ & 6.35 \\
\hline $8 q 22.1-q 23$ & 6 & $6 / 28$ & $4 / 9$ & 9.52 \\
\hline $8 q 24.1$ - qter & 6 & $6 / 28$ & $4 / 9$ & 9.52 \\
\hline$|2 p| 2-p||$ & 6 & $6 / 18$ & $5 / 7$ & 23.81 \\
\hline 12q24.1-qter & 5 & $5 / 18$ & $3 / 7$ & 11.9 \\
\hline $17 q 21.3-q 22$ & 5 & $5 / 14$ & $5 / 8$ & 22.32 \\
\hline
\end{tabular}

$\mathrm{Bl}=$ breakpoint incidence; $\mathrm{RI}=$ recurrence index.

8: $8 \mathrm{p} 11-\mathrm{p} 12,8 \mathrm{q} 10-\mathrm{q} 21.1,8 \mathrm{q} 22.1-\mathrm{q} 23$ and 8q24.1-qter. We identified two frequently altered regions on chromosome 12: 12p11-p12 and 12q24.1-qter. Finally, we identified only one frequently altered region on chromosome 17 , at $17 \mathrm{q} 21.3-\mathrm{q} 22$.

\section{Breakpoint characterisation}

To confirm that mbanding-FISH is a useful means of screening for chromosomal breaks, we selected two of the potential breakpoints, one in the low incidence range and the second in the high incidence range. The $1 \mathrm{p} 36$ and $5 \mathrm{p} 12$ breakpoints of the $t(1 ; 6)(p 36 ; p 21)$ and $t(5 ; 12)(p 12 ; p 11)$ present in IPC-BC-116 and UACC-812 cell lines, respectively, were studied by dual-colour FISH (Figures 2B-C, respectively). Figure 2B shows the results of a dual-colour FISH experiment carried out on metaphase chromosomes from IPC-BC-116 with digoxigenin-labelled DNA of RP11164A22 (revealed in red, TRITC) in combination with biotinylated DNA of RP11-99F3 and centromeric probe specific for chromosome 6 (revealed in green, FITC). The telomeric position of RP11$164 \mathrm{~A} 22$ allowed the identification of normal chromosome 1 and derivative chromosome 6 . The concomitant presence of RP11-99F3 on both derivatives and on chromosome 1 suggested that this clone spans the $1 \mathrm{p} 36$ breakpoint. The RP11-99F3 BAC clone (AC020587) contains the MGC15730 gene (hypothetical protein MGC15730) covering $270 \mathrm{~kb}$. This gene has 10 exons and produces two variant transcripts by alternative splicing (UCSC Genome Browser on Human May 2004 Assembly is based on NCBI Build 35 (National Center for Biotechnology Information, US National Library of Medicine 8600 Rockville Pike, Bethesda, MD, USA)). The biological function of the corresponding putative proteins is not known.

The $\mathrm{t}(5 ; 12)(\mathrm{p} 13 ; \mathrm{p} 11)$ translocation present in UACC-812 targets the most frequently altered region of chromosome 5 (Figure $2 \mathrm{~A}$ ). The FISH analysis using biotinylated DNA of RP11-190J8 BAC clone (AC021600) in combination with the digoxigenin-labelled centromeric probe for chromosome 12 allowed the characterisation of the breakpoint (Figure 2C). The RP11-190J8 BAC clone contains the $5^{\prime}$ part of the LOC345557 gene (XM_293875.4) (similar to RIKEN cDNA B130016010 gene) expressed as two uncharacterised sequences BX648329.1 (7601 bp) and AK127142 (2432 bp). Currently, the biological function of the corresponding putative proteins is not known. Using the SMART software (http:// smart.embl-heidelberg.de/smart/show_motifs.pl), a phospholipase C catalytic domain (noted 'PLCXc') was detected in the XP_293875 protein sequence associated to BX648329.1 mRNA. A link was also found with AK127142, which is probably generated by alternative splicing.

\section{DISCUSSION}

Multicolour-banding approach: towards a better definition of chromosomal rearrangements in breast cancers

The progress of FISH technologies based on chromosome painting, SKY and multiplex-FISH or multicolour-FISH (M-FISH) (Schröck et al, 1996; Speicher et al, 1996) has overcome the limitations of conventional cytogenetic methods in the characterisation of complex chromosome alterations observed in cancers. It offers a simultaneous visualisation of all human chromosomes in different pseudocolours, and allows a better characterisation of the rearrangements. However, the definition of chromosomal abnormalities such as intrachromosomal changes or abnormal chromosomal segments could not be approached with these techniques. To overcome these limitations, different multicolour-banding techniques have been developed such as: (i) mbanding-FISH (also called multicolour banding) (Chudoba et al, 1999; Liehr et al, 2002a, b), which is a modification of M-FISH, (ii) a chromosome bar code technique (Müller et al, 1997), (iii) a crossspecies colourbanding technique called Rx-FISH (Müller et al, 1998) and (iv) a spectral colour banding known as SCAN (Kakazu et al, 2003). These approaches have different levels of banding resolution (Kakazu et al, 2003). Very recently, the resolution of discernable bars was increased to 100 bars per haploid chromosome set by including human chromosome-specific probes and more welldefined subregional probes (Müller et al, 2004). The analysis of chromosomal alterations using these techniques could reveal new aberrations not visible by other methods, and consequently facilitate the molecular characterisation of target genes.

\section{Comparison of our results with literature data}

Our findings correlate well with what is known for chromosome 1. This chromosome is one of the most frequently affected in breast cancers (Dutrillaux et al, 1990; Bièche et al, 1993; Pandis et al, 1995; Teixeira et al, 2002; http://cgap.nci.nih.gov/Chromosomes/ RecurrentAberrations). Analyses of breast tumours have established a frequency of breaks as follows: $1 \mathrm{p} 36(6.5 \%), 1 \mathrm{p} 22(6.1 \%)$, $1 \mathrm{p} 13$ (5.9\%), 1q10 (24\%), 1q11-12 (7\%), 1q21 (9.1\%), 1q25 (5\%) and 1q42 (5.9\%) (Teixeira et al, 2002). Frequent allelic imbalances have been found at $1 \mathrm{p} 36(11 \%), 1 \mathrm{q} 42-44(13-14 \%)$ and amplification is commonly observed at 1q21. The presence of at least four potential tumour suppressor genes (TSG), at 1p13, 1p22, $1 \mathrm{p} 31$ and $1 \mathrm{p} 34$-pter, has been suggested (see for a review, Bièche et al, 1999). Unbalanced translocations affecting chromosome 1 frequently lead to segmental losses, which could target TSG, while oncogenes could be activated by intrachromosomal amplification (essentially on 1q) or by promoting gene fusion.

As opposed to chromosome 1, aberrations of chromosome 5 are relatively rare in breast cancers (http://cgap.nci.nih.gov/Chromosomes/RecurrentAberrations); they target preferentially the $5 \mathrm{p} 15$ region (Teixeira et al, 2002). Allelic imbalances have been reported with gains of $5 \mathrm{p}$ in $39 \%$ of breast tumour cell lines (Forozan et al, 2000). Losses of $5 \mathrm{q}(86 \%)$ are common in BRCA1-mutated tumours (Tirkkonen et al, 1997).

Chromosome 8 aberrations are very frequent in breast tumours, resulting in losses of $8 \mathrm{p}$ and gains of $8 \mathrm{q}$ (Mertens et al, 1995; Adeyinka et al, 2000; Davidson et al, 2000; Forozan et al, 2000; Kytölä et al, 2000; Höglund et al, 2001; Rummukainen et al, 2001; Struski et al, 2002; Teixeira et al, 2002; Ferti et al, 2004; Online CGH Tumour Database; http://cgap.nci.nih.gov/Chromosomes/ RecurrentAberrations). The $8 \mathrm{p} 11-\mathrm{p} 21$ region contains several potential TSG and oncogenes (Adélaïde et al, 1998, 2003; Ugolini et al, 1999; Conte et al, 2002; Ray et al, 2004).

We have recently shown by FISH analysis that NRG1 (8p21) is frequently targeted by recurrent breakpoints in breast tumour cell lines including ZR-75-1 (Adélaïde et al, 2003), and in $6 \%$ of 
primary tumours (Huang et al, 2004). Moreover, studies by Courtay-Cahen et al (2000), as well as our work (Adélaïde et al, 2003 , and data not shown), have suggested the frequent presence of breakpoints located centromeric to NRG1 (Gelsi-Boyer et al, in preparation). Thus, all breakpoint found in this region using mbanding-FISH were confirmed by FISH using BAC clones showing again that mbanding-FISH is reliable to map breakpoints.

Multiplication of the entire $8 \mathrm{q}$ arm and regional amplifications on $8 \mathrm{q}$ are common features in breast cancer (Kallioniemi et al, 1994; Mark et al, 1997). The majority of 8q amplicons encompass $8 \mathrm{q} 24$, and comprise the MYC oncogene (8q24.12) (Yokota et al, 1999; Forozan et al, 2000). However, several studies have shown the presence of other amplicons at 8q21, 8q22-23 and 8q24 (Kallioniemi et al, 1994; Muleris et al, 1994; Fejzo et al, 1998, Nupponen et al, 1999; Forozan et al, 2000; Seute et al, 2001), possibly associated with the presence of several common fragile sites (Hellman et al, 2002).

Reciprocal translocations $\mathrm{t}(8 ; 12)(\mathrm{q} 24 ; \mathrm{p} 12), \mathrm{t}(12 ; 14)(\mathrm{p} 11 ; \mathrm{q} 11)$ and $\mathrm{t}(12 ; 21)(\mathrm{p} 12 ; \mathrm{q} 22)$ have been reported in breast diseases (Rohen et al, 1993; see for reviews Petersson et al, 1997; Cavalli et al, 2001; http://cgap.nci.nih.gov/Chromosomes/RecurrentAberrations). The $12 \mathrm{p} 13,12 \mathrm{q} 12$ and $12 \mathrm{q} 24$ regions have the highest frequencies of breaks (Teixeira et al, 2002). In SK-BR-3, the derivative $\operatorname{der}(12) \mathrm{t}(3 ; 12)$ has been previously identified by SKY FISH (Kytölä et al, 2000). The use of mbanding-FISH contributed to facilitate the detection of the inversion and finally to characterise this derivative as $\operatorname{del}(12)(\mathrm{q} 24.2) \operatorname{inv}(12)(\mathrm{p} 11 \mathrm{q} 24.2)$ $t(3 ; 12)(? ; p 11)$.

Chromosome 17 is often the target of amplification at q12-21 and q23 (Forozan et al, 2000; Seute et al, 2001), and of unbalanced translocations (Kytölä et al, 2000). Among the characterised chromosomal rearrangements, the BCAS4-BCAS3 fusion transcript has been detected only in MCF-7 cells (Bärlund et al, 2002). In our study, a dup(17)(q25q21.3) was detected in UACC-812.

\section{REFERENCES}

Adélaïde J, Chaffanet M, Imbert A, Allione F, Geneix J, Popovici C, van Alewijk D, Trapman J, Zeillinger R, Borresen-Dale AL, Lidereau R, Birnbaum D, Pébusque MJ (1998) Chromosome region 8p11-p21: refined mapping and molecular alterations in breast cancer. Genes Chromosomes Cancer 22: 186-199

Adélaïde J, Huang HE, Murati A, Alsop AE, Orsetti B, Mozziconacci MJ, Popovici C, Ginestier C, Letessier A, Basset C, Courtay-Cahen C, Jacquemier J, Theillet C, Birnbaum D, Edwards PA, Chaffanet M (2003) A recurrent chromosome translocation breakpoint in breast and pancreatic cancer cell lines targets the neuregulin/NRG1 gene. Genes Chromosomes Cancer 37: $333-345$

Adeyinka A, Kytola S, Mertens F, Pandis N, Larsson C (2000) Spectral karyotyping and chromosome banding studies of primary breast carcinomas and their lymph node metastases. Int J Mol Med 5: 235-240

Bärlund M, Monni O, Weaver JD, Kauraniemi P, Sauter G, Heiskanen M, Kallioniemi O-P, Kallioniemi A (2002) Cloning of BCAS3 (17q23) and BCAS4 (20q13) genes that undergo amplification, overexpression, and fusion in breast cancer. Genes Chromosomes Cancer 35: 311-317

Bièche I, Champeme MH, Matifas F, Cropp CS, Callahan R, Lidereau R (1993) Two distinct regions involved in 1p deletion in human primary breast cancer. Cancer Res 53: 1990-1994

Bièche I, Khodja A, Lidereau R (1999) Deletion mapping of chromosomal region 1p32-pter in primary breast cancer. Genes Chromosomes Cancer 24: $255-263$

Cavalli LR, Cornelio DA, Wuicik L, Bras AT, Ribeiro EM, Lima RS, Urban CA, Rogatto SR, Cavalli IJ (2001) Clonal chromosomal alterations in fibroadenomas of the breast. Cancer Genet Cytogenet 131: 120-124

Chudoba I, Plesch A, Lorch T, Lemke J, Claussen U, Senger G (1999) High resolution multicolour-banding: a new technique for refined FISH analysis of human chromosomes. Cytogenet Cell Genet 84: 156-160

Conte N, Charafe-Jauffret E, Delaval B, Adélaïde J, Ginestier C, Geneix J, Isnardon D, Jacquemier J, Birnbaum D (2002) Carcinogenesis and
In conclusion, mbanding-FISH is a useful approach to localise recurrent chromosome alterations throughout the genome. However, the relevance of these alterations to oncogenesis is not unambiguous. Some breakpoints may be associated to genome instability and be part of a background of alterations that do not involve cancer genes. In contrast, some other breakpoints may be associated to bona fide cancer genes. They may or may not involve fragile sites (Huebner and Croce, 2001; Richards, 2001; Dhillon et al, 2003). It is thus likely that we have identified both relevant and irrelevant alterations. In the case of breaks that occur at $8 \mathrm{p} 12$, we know that some do target potential cancer genes and are found in tumour samples (Huang et al, 2004). The two cases of break we studied in greater detail targeted genes with unknown function. More work is required to determine whether these alterations are involved in oncogenesis. The identification of regions of breaks may provide a repertoire of alterations whose study may reveal interesting candidates.

\section{ACKNOWLEDGEMENTS}

We thank S Ethier and V Möbus for the gift of the SUM and BrCa-MZ-01 breast tumour cell lines, respectively. We are grateful to F Birg, D Maraninchi and C Mawas for encouragement and advices, and to JM. Durey for help with the illustrations. This work was supported by Institut Paoli-Calmettes, Inserm, Ministries of Research and Health (Cancéropôle) and grants from Association pour la Recherche sur le Cancer and Ligue Nationale Contre le Cancer (Label). AL is the recipient of a fellowship from the Ligue Nationale Contre le Cancer.

Supplementary Information accompanies the paper on British Journal of Cancer website (http://www.nature.com/bjc) translational controls: TACC1 is down-regulated in human cancers and associates with mRNA regulators. Oncogene 21: 5619-5630

Courtay-Cahen C, Morris JS, Edwards PAW (2000) Chromosome translocations in breast cancer with breakpoints at $8 \mathrm{p} 12$. Genomics 66: $15-25$

Davidson JM, Gorringe KL, Chin SF, Orsetti B, Besret C, Courtay-Cahen C, Roberts I, Theillet C, Caldas C, Edwards PAW (2000) Molecular cytogenetic analysis of breast cancer cell lines. Br J Cancer 83: 1309-1317

Devilee P, Cleton-Jansen AM, Cornelisse CJ (2001) Ever since Knudson. Trends Genet 17: 569-573

Dhillon VS, Husain SA, Ray GN (2003) Expression of aphidicolin-induced fragile sites and their relationship between genetic susceptibility in breast cancer, ovarian cancer, and non-small-cell lung cancer patients. Teratogen Carcinogen Mutagen 23: $35-45$

Dutrillaux B, Gerbault-Seureau M, Zafrani B (1990) A comparison of 30 paradiploid cases with few chromosome changes. Cancer Genet Cytogenet 49: 203-217

Fejzo MS, Godfrey T, Chen C, Waldman F, Gray JW (1998) Molecular cytogenetic analysis of consistent abnormalities at $8 \mathrm{q} 12-\mathrm{q} 22$ in breast cancer. Genes Chromosomes Cancer 22: 105-113

Ferti AD, Stamouli MI, Panani AD, Ferti AD, Raptis SA, Young BD (2004) Molecular cytogenetic analysis of breast cancer: a combined multicolour fluorescence in situ hybridisation and G-banding study of uncultured tumour cells. Cancer Genet Cytogenet 149: 28-37

Forozan F, Mahlamaki EH, Monni O, Chen Y, Veldman R, Jiang Y, Gooden GC, Ethier SP, Kallioniemi A, Kallioniemi OP (2000) Comparative genomic hybridization analysis of 38 breast cancer cell lines: a basis for interpreting complementary DNA microarray data. Cancer Res 60: $4519-4525$

Forozan F, Veldman R, Ammerman CA, Parsa NZ, Kallioniemi A, Kallioniemi OP, Ethier SP (1999) Molecular cytogenetic analysis of 11 new breast cancer cell lines. Br J Cancer 81: $1328-1334$ 
Hellman A, Zlotorynski E, Scherer SW, Cheung J, Vincent JB, Smith DI, Trakhtenbrot L, Kerem B (2002) A role for common fragile site induction in amplification of human oncogenes. Cancer Cell 1: 89-97

Höglund M, Gisselsson D, Mandahl N, Johansson B, Mertens F, Mitelman F, Sall T (2001) Multivariate analyses of genomic imbalances in solid tumours reveal distinct and converging pathways of karyotypic evolution. Genes Chromosomes Cancer 31: 156-171

Huang HE, Chin S-F, Ginestier C, Bardou V-J, Adelaide J, Iyer NG, Garcia MJ, Pole JC, Callagy GM, Hewitt SM, Gullick WJ, Jacquemier J, Caldas C, Chaffanet M, Birnbaum D, Edwards PA (2004) A recurrent chromosome breakpoint in breast cancer at the NRG1/neuregulin 1/heregulin gene. Cancer Res 64: 6840-6844

Huebner K, Croce CM (2001) FRA3B and other common fragile sites: the weakest links. Nat Rev Cancer 1: 214-221

ISCN (1995) In An International System for Human Cytogenetic Nomenclature, Mitelman F (ed) Basel: S Karger

Kakazu N, Bar-Am I, Hada S, Ago H, Abe T (2003) A new chromosome banding technique, spectral colour banding (SCAN), for full characterization of chromosomal abnormalities. Genes Chromosomes Cancer 37: $412-416$

Kallioniemi OP, Kallioniemi A, Piper J, Isola J, Waldman FM, Gray JW, Pinkel D (1994) Optimizing comparative genomic hybridization for analysis of DNA sequence copy number changes in solid tumours. Genes Chromosomes Cancer 10: 231-243

Kytölä S, Rummukainen J, Nordgren A, Karhu R, Farnebo F, Isola J, Larsson C. (2000) Chromosomal alterations in 15 breast cancer cell lines by comparative genomic hybridization and spectral karyotyping. Genes Chromosomes Cancer 28: 308-317

Liehr T, Heller A, Starke H, Rubtsov N, Trifonov V, Mrasek K, Weise A, Kuechler A, Claussen U (2002b) Microdissection based high resolution multicolour banding for all 24 human chromosomes. Int J Mol Med 9: $335-339$

Liehr T, Weise A, Heller A, Starke H, Mrasek K, Kuechler A, Weier HU, Claussen U (2002a) Multicolour chromosome banding (MCB) with YAC/ BAC-based probes and region-specific microdissection DNA libraries. Cytogenet Genome Res 97: 43-50

Mark HF, Taylor W, Afify A, Riera D, Rausch M, Huth A, Gray Y, Santoro K, Bland KI (1997) Stage I and stage II infiltrating ductal carcinoma of the breast analyzed for chromosome 8 copy number using fluorescent in situ hybridization. Pathobiology 65: 184-189

Mertens F, Johansson M, Mitelman F (1995) The pathogenetic significance of acquired trisomy 8 is not reducible to amplification of a single chromosome band. Cancer Genet Cytogenet 83: 176-177

Möbus VJ, Moll R, Gerharz CD, Kieback DG, Merk O, Runnebaum IB, Linner S, Dreher L, Grill HJ, Kreienberg R (1998) Differential characteristics of two new tumourigenic cell lines of human breast carcinoma origin. Int $J$ Cancer 77: 415-423

Müller S, Eder V, Wienberg J (2004) A nonredundant multicolour bar code as a screening tool for rearrangements in neoplasia. Genes Chromosomes Cancer 39: $59-70$

Müller S, O'Brien PC, Ferguson-Smith MA, Wienberg J (1998) Crossspecies colour segmenting: a novel tool in human karyotype analysis. Cytometry 33: $445-452$

Müller S, Rocchi M, Ferguson-Smith MA, Wienberg J (1997) Toward a multicolour chromosome bar code for the entire human karyotype by fluorescence in situ hybridization. Hum Genet 100: 271-278

Muleris M, Almeida A, Gerbault-Seureau M, Malfoy B, Dutrillaux B (1994) Detection of DNA amplification in 17 primary breast carcinomas with homogeneously staining regions by a modified comparative genomic hybridization technique. Genes Chromosomes Cancer 10: 160-170

Nupponen NN, Porkka K, Kakkola L, Tanner M, Persson K, Borg A, Isola J, Visakorpi T (1999) Amplification and overexpression of p40 subunit of eukaryotic translation initiation factor 3 in breast and prostate cancer. Am J Pathol 154: 1777 - 1783

Online CGH Tumour Database. http://amba.charite.de/ ksch/cghdatabase/ index.htm
Pandis N, Jin Y, Gorunova L, Petersson C, Bardi G, Idvall I, Johansson B, Ingvar C, Mandahl N, Mitelman F, Heim S (1995) Chromosome analysis of 97 primary breast carcinomas: identification of eight karyotypic subgroups. Genes Chromosomes Cancer 12: 173-185

Petersson C, Pandis N, Rizou H, Mertens F, Dietrich CU, Adeyinka A, Idvall I, Bondeson L, Georgiou G, Ingvar C, Heim S, Mitelman F (1997) Karyotypic abnormalities in fibroadenomas of the breast. Int J Cancer 70 : $282-286$

Popovici C, Basset C, Bertucci F, Orsetti B, Adelaide J, Mozziconacci MJ, Conte N, Murati A, Ginestier C, Charafe-Jauffret E, Ethier SP, LafagePochitaloff M, Theillet C, Birnbaum D, Chaffanet M (2002) Reciprocal ranslocations in breast tumour cell lines: cloning of a $t(3 ; 20)$ that targets the FHIT gene. Genes Chromosomes Cancer 35: 204-218

Richards RI (2001) Fragile and unstable chromosomes in cancer: causes and consequences. Trends Genet 17: 339-345

Rummukainen J, Kytola S, Karhu R, Farnebo F, Larsson C, Isola JJ (2001) Aberrations of chromosome 8 in 16 breast cancer cell lines by comparative genomic hybridization, fluorescence in situ hybridization, and spectral karyotyping. Cancer Genet Cytogenet 126: 1-7

Ray ME, Yang ZQ, Albertson D, Kleer CG, Washburn JG, Macoska JA, Ethier SP. (2004) Genomic and expression analysis of the 8p11-12 amplicon in human breast cancer cell lines. Cancer Res 64: 40-47

Rohen C, Bonk U, Staats B, Bartnitzke S, Bullerdiek J (1993) Two human breast tumours with translocations involving $12 \mathrm{q} 13-15$ as the sole cytogenetic abnormality. Cancer Genet Cytogenet 69: 68-71

Schröck E, du Manoir S, Veldman T, Schoell B, Wienberg J, FergusonSmith MA, Ning Y, Ledbetter DH, Bar-Am I, Soenksen D, Garini Y, Ried $\mathrm{T}$ (1996) Multicolour spectral karyotyping of human chromosomes. Science 273: $494-497$

Seute A, Sinn HP, Schlenk RF, Emig R, Wallwiener D, Grischke EM, Hohaus S, Dohner H, Haas R, Bentz M (2001) Clinical relevance of genomic aberrations in homogeneously treated high-risk stage II/III breast cancer patients. Int $J$ Cancer 93: 80-84

Speicher MR, Ballard SG, Ward DC (1996) Karyotyping human chromosomes by combinatorial multi-fluor FISH. Nat Genet 12: 368-375

Struski S, Doco-Fenzy M, Cornillet-Lefebvre P (2002) Compilation of published comparative genomic hybridization studies. Cancer Genet Cytogenet 135: 63-90

Teixeira MR, Pandis N, Heim S (2002) Cytogenetic clues to breast carcinogenesis. Genes Chromosomes Cancer 33: 1-16

Tirkkonen M, Johannsson O, Agnarsson BA, Olsson H, Ingvarsson S, Karhu R, Tanner M, Isola J, Barkardottir RB, Borg A, Kallioniemi OP (1997) Distinct somatic genetic changes associated with tumour progression in carriers of BRCA1 and BRCA2 germ-line mutations. Cancer Res 57: 1222-1227

Tognon C, Knezevich SR, Huntsman D, Roskelley CD, Melnyk N, Mathers JA, Becker L, Carneiro F, MacPherson N, Horsman D, Poremba C, Sorensen PH (2002) Expression of the ETV6-NTRK3 gene fusion as a primary event in human secretory breast carcinoma. Cancer Cell 2: 367-376

Tomlinson GE, Chen TT, Stastny VA, Virmani AK, Spillman MA, Tonk V, Blum JL, Schneider NR, Wistuba II, Shay JW, Minna JD, Gazdar AF (1998) Characterization of a breast cancer cell line derived from a germline BRCA1 mutation carrier. Cancer Res 58: 3237-3242

Ugolini F, Adélaïde J, Charafe-Jauffret E, Nguyen C, Jacquemier J, Jordan B, Birnbaum D, Pébusque MJ (1999) Differential expression assay of chromosome arm $8 \mathrm{p}$ genes identifies Frizzled-related (FRP1/FRZB) and fibroblast growth factor receptor 1 (FGFR1) as candidate breast cancer genes. Oncogene 18: 1903-1910

Wang XZ, Jolicoeur E, Conte N, Chaffanet M, Zhang Y, Mozziconacci MJ, Feiner H, Birnbaum D, Pébusque MJ, Ron D (1999) $\gamma$-heregulin is the product of a chromosomal translocation fusing the DOC4 and $H G L /$ NRG1 genes in the MDA-MB-175 breast cancer cell line. Oncogene 18: $5718-5721$

Yokota T, Yoshimoto M, Akiyama F, Sakamoto G, Kasumi F, Nakamura Y, Emi M (1999) Frequent multiplication of chromosomal region 8q24.1 associated with aggressive histologic types of breast cancers. Cancer Lett 139: $7-13$ 